\title{
Using Always Events to derive patient- centred quality improvement priorities in a specialist primary care service providing care to a homeless population
}

\author{
Marianne McCallum, ${ }^{\oplus 1}$ Duncan McNab, ${ }^{2}$ John Mckay $^{2}$
}

To cite: McCallum M, McNab D, Mckay J. Using Always Events to derive patient-centred quality improvement priorities in a specialist primary care service providing care to a homeless population. BMJ Open Quality 2019;8:e00507. doi:10.1136/ bmjoq-2018-000507

Received 15 August 2018 Revised 12 December 2018 Accepted 2 January 2019

\section{Check for updates}

(c) Author(s) (or their employer(s)) 2019. Re-use permitted under CC BY-NC. No commercial re-use. See rights and permissions. Published by BMJ.

${ }^{1}$ General Practice and Primary Care, Institute of Health and Wellbeing, University of Glasgow, Glasgow, UK ${ }^{2}$ Medical Directorate, NHS Education for Scotland West Region, Glasgow, UK

Correspondence to Dr Marianne McCallum; marianne.mccallum@glasgow. ac.uk

\section{ABSTRACT}

Background 'Always Events' (AE) is a validated quality improvement (QI) method where patients, and/or carers, are asked what is so important that it should 'always' happen when they interact with healthcare services. Answers that meet defined criteria can be used to direct patient-centred Ql activities. This method has never, to our knowledge, been applied in the care of a UK homeless population. We aimed to test the aspects of the acceptability and feasibility of the AE method to inform on its potential application to improve care for this vulnerable group of patients.

Methods All patients attending three consecutive drop-in clinics at a specialist homeless general practitioner service in Glasgow, who agreed to participate, were interviewed. Anonymised responses were transcribed and coded and a thematic analysis performed. Themes were summarised to generate candidate $\mathrm{AE}$ using the patient's own words. The authors then determined if they met the AE criteria.

Results Twenty out of 22 eligible patients were interviewed. Oral transcribing was found to be an acceptable way to gather data in this group. Nine candidate AEs were generated, of which five fitted the criteria to be used as metrics for future QI projects. This project generated AEs and QI targets, and highlighted issues of importance to patients that could be easily addressed.

Conclusion In the homeless context, obtaining high engagement and useful patient feedback, in a convenient way, is difficult. The AE method is an acceptable and feasible tool for generating QI targets that can lead to improvements in care for this vulnerable group.

\section{BACKGROUND}

The use of quality improvement (QI) initiatives to drive improvement in primary care is a national priority. ${ }^{12}$ Clinicians, based on their priorities or local and national guidance, direct the majority of QI projects. QI activities can be resource intensive but risk being misdirected if not targeted at care issues that are important to those that use the service. ${ }^{3}$ The Always Events $(\mathrm{AE})^{4}$ concept takes a person-centred approach to QI where patients or carers identify what is so important to them that it should always happen when interacting with health and care services. An example of an AE would be 'I always want to get through to my general practitioner (GP) reception on the telephone quickly.' The concept (or method) was developed by the US-based Picker Institute ${ }^{5}$ to enable healthcare providers to identify and contextualise their own patients' priorities. Identification of these priority areas for patients offers the opportunity for providers to generate QI metrics and/or signpost them to direct and implement improvement efforts. This 'open engagement ${ }^{4}$ approach allows the development of QI activities that are important to their patient population, specific but adaptable to their particular healthcare context. A previous study established the feasibility of this approach in primary care in National Health Service (NHS) Scotland. ${ }^{4}$ It adapted the original $\mathrm{AE}$ concept and criteria so that patient-identified improvement suggestions must fulfil the following criteria in order to be considered an $\mathrm{AE}^{4}$ :

- Any healthcare interaction, process or outcome that is judged by patients, carers or relatives to be a highly important determinant of care quality and experience.

- Feasible as part of routine healthcare delivery.

- Unambiguous and specific to enable reliable measurement.

- Consistently deliverable to applicable patient groups by all relevant healthcare organisations, teams and individuals.

The mix of people who experience homelessness are often vulnerable and struggle to access mainstream primary care ${ }^{6-13}$ Multiple specialist homeless health services have been set up across the UK to try to improve health access for this population, of which many are allied to the Faculty of Health Inclusion. ${ }^{14}$ The faculty has produced a series of standards for primary healthcare in this group based on nine values. ${ }^{15}$ These include recognising the 
importance of services committing to regular reflection and learning, ${ }^{15}$ allowing this to drive, and continuously measure, change. ${ }^{16}$ Due to the degree of social exclusion, and barriers faced by this population patient-centred services, designed with service user involvement, are recognised to be especially important. ${ }^{791516}$ Given the patient-centred ethos of the AE method, it was felt it may be particularly suitable in this patient group. Although the feasibility of the AE approach has been established, ${ }^{4}$ it has never been tested in a healthcare setting for the homeless population.

\section{AIM}

To determine if the $\mathrm{AE}$ concept is an acceptable and feasible method for deriving patient-centred QI priorities in a specialist primary care service providing care to a homeless population.

\section{METHODS}

\section{Setting and participants}

Consecutive attenders at three GP drop-in surgeries at a specialist primary care service for homeless people in Glasgow were invited to take part.

\section{Data collection}

$\mathrm{AE}$ projects have previously used paper questionnaires for participants to complete. Due to the anticipated lower literacy rates in this population it was decided to interview patients to asses this aspect of acceptability and feasibility of data gathering. All patients were asked if they would be willing to take a few minutes to answer some questions related to the service. If they agreed a healthcare assistant (HCA), known to participants, interviewed them in a private room. Patient responses were then written down by the HCA, using their own words.

The HCA was given a briefing beforehand about the $\mathrm{AE}$ concept and she read a short written explanation to patients before asking them, 'What is so important to you that it should ALWAYS happen when you visit this GP surgery?' Responses were then written down by the HCA and she was able to ask follow-up questions to clarify, which were also transcribed. Responses were analysed iteratively until data saturation was achieved.

\section{Data analysis}

Generation of AE themes

A systematic and iterative approach to analysis of the collected data, based on the inductive thematic analysis method, ${ }^{17}$ was adopted. Responses were anonymised and transcribed. Collected data were read and re-read by MM to facilitate a deep understanding of the data. Codes were assigned to the data by MM, which were discussed with all authors to negotiate and construct themes. The actual words used by participants at interview were used to describe themes. These were defined as candidate AE.

\section{Comparison to AE criteria}

All authors rated the candidate AEs against the AE criteria independently and then met to discuss each in turn. To be classified as an $\mathrm{AE}$, all authors had to agree that the candidate $\mathrm{AE}$ met all the criteria.

\section{RESULTS}

Twenty-two patients attended the three drop-in clinics. Two were not able to take part due to high levels of intoxication but all the other patients agreed to participate resulting in 20 respondents. Participants gave between one and six suggestions, with a mean of 3 .

Nine candidate AEs were generated of which five were deemed to fulfil the criteria for an $\mathrm{AE}$, demonstrated in table 1 .

The five AEs were discussed, with the service management team; comprising the leads of the different clinical teams that worked within the service (including addictions, mental health, occupational therapy), as well as all members of the GP team. 'I always want to

Table 1 Final agreement on application of Always Events criteria to candidate Always Events (agreed Always Events listed first)

\begin{tabular}{|c|c|c|c|c|c|}
\hline \multirow[b]{2}{*}{$\begin{array}{l}\text { Candidate Always Events } \\
\text { I always want ... }\end{array}$} & \multicolumn{5}{|c|}{ Always Events criteria } \\
\hline & $\begin{array}{l}\text { Highly important } \\
\text { healthcare } \\
\text { interaction }\end{array}$ & Feasible & $\begin{array}{l}\text { Unambiguous } \\
\text { and specific }\end{array}$ & $\begin{array}{l}\text { Consistently } \\
\text { deliverable }\end{array}$ & $\begin{array}{l}\text { Always } \\
\text { Events? }\end{array}$ \\
\hline To be seen & $\sqrt{ }$ & $\sqrt{ }$ & $\sqrt{ }$ & $\sqrt{ }$ & $\sqrt{ }$ \\
\hline The staff to be approachable and responsive & $\sqrt{ }$ & $\sqrt{ }$ & $\sqrt{ }$ & $\sqrt{ }$ & $\sqrt{ }$ \\
\hline To feel safe while waiting to be seen & $\sqrt{ }$ & $\sqrt{ }$ & $\sqrt{ }$ & $\sqrt{ }$ & $\sqrt{ }$ \\
\hline Clear information on how service works & $\sqrt{ }$ & $\sqrt{ }$ & $\sqrt{ }$ & $\sqrt{ }$ & $\sqrt{ }$ \\
\hline The appointment system to be fair & $\sqrt{ }$ & $\sqrt{ }$ & $x$ & $x$ & $\mathrm{x}$ \\
\hline To be treated with dignity and not stigmatised & $\sqrt{ }$ & $\sqrt{ }$ & $\times$ & $\sqrt{ }$ & $\times$ \\
\hline The staff to listen to me & $\sqrt{ }$ & $\sqrt{ }$ & $x$ & $\sqrt{ }$ & $x$ \\
\hline
\end{tabular}


Box 1 Expanded examples of impact of Always Events

\section{I always want to be seen.}

I always want to get seen was far and away the most consistent feedback we got from almost all the patients: there was a real concern they would not get seen:

Sometimes people not getting seen as others are pushing past.

Get seen—get frustrated if can't get seen as too many people.

Get seen. I sometimes 'skip' but that's so can get away quicker. Previous time I was followed and attacked after being in the GP clinic. That was my own fault though.

This was surprising for staff as the service was set up so that everyone would get seen, though not necessarily by a GP. The feedback from this short intervention showed that actually many of our patients thought they would not get seen, and therefore felt that bullying and queue jumping was justified.

The service has responded to this AE by:

- Increasing staffing levels for the afternoon drop-in clinic.

- Putting up posters in waiting room and providing information in easy-to-read formats on how the service works.

- Speaking to key third sector partners who support and signpost services to this population to ensure they understand service, and are able to correct any misunderstandings.

The service plans to use the data from this project as baseline data (proportion of people who thought they would always get seen was $0 \%$ ). After the above intervention they plan on surveying patients again, and instituting further changes, as required, and using further audit cycles aiming for a standard of $90 \%$.

\section{I always want to feel safe while waiting to be seen.}

This theme was mentioned by several of the patients who did not feel safe in the waiting room, or the queue outside.

Don't like looking at people, there is nowhere to look at without looking at someone else... feels confrontational. An argument happened today as someone thought somebody else staring at them.

Too many people hanging about, everyone needs seen for whatever reason so don't know how it can be better.

I felt waiting outside was a bit 'savage'. I thought someone was going to get killed. Wasn't very nice and people jumping the queue.

The service had been aware that there had been incidents in the queue, and the waiting room, but the feedback in the patient's own words was a powerful incentive for the service to look at ways to adapt the service. It was felt the issues of 'bottlenecks' where lots of people were waiting to be seen for a prolonged period of time was important. The service consulted with other similar services about different ways of providing appointments. They then consulted staff as to the feasibility of providing on the day appointments instead. A survey of consecutive patients attending the drop-in revealed that 53 of 60 patients' survey would also prefer on-the-day appointments.

Given the above, the service is currently discussing how they are going to implement a change in the appointment system and evaluate it. In direct response to the comment regarding 'nowhere to look' (and mentions of boredom discussed earlier) the service is adding a TV to the waiting room which will provide information on relevant health and third sector services. Patients will be consulted after implementation asking if they feel safe using the service, and if not asking why.

$\mathrm{AE}$, Always Events; GP, general practitioner.

be seen' was chosen by the service as an initial focus as all respondents mentioned it. 'I always want to feel safe' was also identified by the service as being something they wished to address quickly. The impact of how they were applied to the service is expanded, as an example, in box 1 .

Feedback that did not meet AE criteria still provided useful information that was used by the service to make immediate changes. Boredom, which some patients felt contributed to fights and disagreements in the waiting area, was an issue that was felt could be easily improved by installing a television. Concerns about privacy and being overheard when booking in have led to a change in the way patients are asked their personal details, ensuring people cannot be overheard.

\section{DISCUSSION}

The aim of this project was to see if this method was a feasible way of deriving patient-centred QI targets in the homeless population. This study showed that it was feasible, quickly highlighting concerns and priorities, for the patients in a way that seemed to be acceptable to them. The HCA enjoyed conducting the interviews, there was minimal training required and she felt it was acceptable as part of her everyday work.

\section{Strengths and limitations}

The method suited many of our patients as it was very quick, and the open-ended questions allowed the service to get more details than previous surveys where patients either tended to answer they thought the service was good 
and had no other comments, or said they did not have time to take part. In contrast, there were high levels of engagement, with only two patients unable to take part, and a lot of valuable feedback was generated very quickly, allowing changes to be implemented rapidly.

Although designing and implementing improvement interventions to some of the AEs will not be easy, the feedback, in the patients' own words, is a powerful lever for improvement work.

Although suggestions for priorities were quickly generated, the method does not allow in-depth analysis/exploration; other methods, such as focus groups, would be required if the service felt more detailed information was required. However, these would involve a more self-selecting group; the advantage of this project was that it covered almost everyone who consecutively used the service and included the views of patients who may not have been willing to sit down for a longer discussion.

One limitation of the project was that we did not formally evaluate the time taken to inform and 'train' the healthcare team to collect and analyse the data. In addition, although we had explained the project to the management team, who were happy to trial the feasibility of data collection, there was no discussion on the capacity of the unit to deliver on the 'Always Events' suggested. This project coincided with changes in the structuring of other teams within the service meaning that immediate action on most of the targets was not possible.

Another limitation was that we did not note the age and demographics of the patients interviewed. The service parameters are open to both men and women over 18 who are homeless, and the study population was recruited by asking everyone who attended three consecutive clinics, so the group is likely to be typical of the homeless population of the UK.

A further limitation was that the patients knew the HCA. While this may have had a positive influence on patient engagement, it is not possible to determine whether the lack of independence from the service may have impacted on what people were willing to say. Good relationships and trust between patients and professionals are very important in this context, and it was hoped that by using an HCA known to them patients would feel more comfortable, and be more willing to be involved. However, it was also recognised that this lack of independence from the service might impact the responses given.

The application of AE has not, as yet, allowed measurement of definite change in the service it was piloted in. However, the main aim of this study was as a feasibility pilot to determine whether this method was applicable in this context. Further work is required to follow-up the implementation of the $\mathrm{AE}$ to establish if this creates sustained change. The new appointment system is due to be introduced soon; ongoing evaluation of this is planned after this study. This will include specifically asking whether patients feel they are 'always' able to be seen, and feel safe when doing so. Further work is also needed to see if it is as effective in other similar populations

\section{Comparison to previous literature}

This particular QI method has not been applied in the Homeless setting before, however the importance of personalised, patient-centred care that is flexible has long been recognised as key for this group. ${ }^{7916} \mathrm{It}$ is not surprising that this patient-centred flexible method was very acceptable to the patients who participated.

The importance of hearing the patient's voice in QI is recognised, particularly for those who are poor, disadvantaged and marginalised. ${ }^{3}$ This method also fits with some of the Faculty of Inclusion Health's values: patient-centred care, a culture of reflection and learning that drives change. ${ }^{15}$ It demonstrates an acceptable way of doing so in this population that experiences considerable social exclusion. It also builds on ongoing work to use QI to drive and generate change in homeless health services. ${ }^{16}$

Other healthcare systems have adapted the AE method: NHS England ${ }^{18}$ used observation, shadowing and focus groups to gain information on patient experience and to generate candidate $\mathrm{AE}$. These could be used in this context to increase the variety of data generated. However, the patient-centred short question does appear to be one of the things that particularly worked in this population, evidenced by our high engagement

\section{CONCLUSION}

The AE method can be successfully used in within a specialist primary care service, providing care to the homeless population, to identify patient priorities for QI and was feasible as part of everyday work. Further work is required to evaluate the changes implemented.

Acknowledgements The authors thank the staff and the patients at Hunter Street Homeless Health Services for facilitating this work.

Contributors MM, DM and JM planned the study. MM organised and oversaw the Always Events interviews. All authors were involved in thematic analysis and generation of the Always Events. MM drafted the manuscript and all authors were involved in revision.

Funding MM was an NHS Education for Scotland Health Inequality Fellow funded from August 2016 to August 2017.

Competing interests None declared.

Patient consent for publication Not required.

Ethics approval Under UK research governance regulations ethical review is not required as following application of the Medical Research Council 'Decision tool-is it research?' The authors considered this project to be service evaluation.

Provenance and peer review Not commissioned; externally peer reviewed. Data sharing statement № additional data are available.

Open access This is an open access article distributed in accordance with the Creative Commons Attribution Non Commercial (CC BY-NC 4.0) license, which permits others to distribute, remix, adapt, build upon this work non-commercially, and license their derivative works on different terms, provided the original work is properly cited, appropriate credit is given, any changes made indicated, and the use is non-commercial. See: http://creativecommons.org/licenses/by-nc/4.0/.

\section{REFERENCES}

1. Scottish Patient Safety Programme. 2017 [cited 2018 Apr 8]. Available: http://www.scottishpatientsafetyprogramme.scot.nhs.uk/

2. Scottish Government. Improving together: A National Framework for Quality and GP Clusters in Scotland. Edinburgh, 2017. 
3. Berwick DM. Era 3 for medicine and health care. JAMA 2016;315:1329-30.

4. Bowie P, McNab D, Ferguson J, et al. Quality improvement and person-centredness: a participatory mixed methods study to develop the 'always event'concept for primary care. BMJ Open 2015;5:e006667.

5. Picker Institute. Always events: creating an optimal patient experience. 2011 [cited 201820 Nov]. Available: https://www.picker. org/always-events/

6. Fazel S, Geddes JR, Kushel M. The health of homeless people in high-income countries: descriptive epidemiology, health consequences, and clinical and policy recommendations. Lancet 2014;384:1529-40.

7. Heatherington KHN. ScotPHNreport. Restoring the Public Health response to Homelessness in Scotland. Glasgow, 2015.

8. Hwang SW, Burns T. Health interventions for people who are homeless. Lancet 2014;384:1541-7.

9. Luchenski S, Maguire N, Aldridge RW, et al. What works in inclusion health: overview of effective interventions for marginalised and excluded populations. Lancet 2018;391:266-80.

10. Aldridge RW, Story A, Hwang SW, et al. Morbidity and mortality in homeless individuals, prisoners, sex workers, and individuals with substance use disorders in high-income countries: a systematic review and meta-analysis. Lancet 2018;391:241-50.

11. Bramley G, Fitzpatrick S, Edwards J, et al. Hard Edges: Mapping severe and multiple disadvantage in England. 2015.

12. Fitzpatrick S, Bramley G, Johnsen S. Pathways into Multiple Exclusion Homelessness in Seven UK Cities. Urban Stud 2013;50:148-68.

13. Fitzpatrick S, Johnsen S, White M. Multiple Exclusion Homelessness in the UK: Key Patterns and Intersections. Social Policy and Society 2011;10:501-12.

14. Pathway. Pathway - The Faculty of Inclusion Health. 2017 [cited 2018 Jan 16]. http://www.pathway.org.uk/faculty/.

15. The Faculty for Homeless and Inclusion Health. Standards for Commisioners and service Providers: self assessment tool for primary care providers. London, 2015.

16. RJA consultancy P, CQC, College of Medicine, Homeless Healthcare $\mathrm{CIC}$, Department of Communities and Local Government. Psychologically informed services for homeless people: Good Practice Guide. 2012.

17. Braun V, Clarke V. Using thematic analysis in psychology. Qual Res Psychol 2006;3:77-101.

18. Institute for Healthcare Improvement. Always Events Toolkit. 2016. 